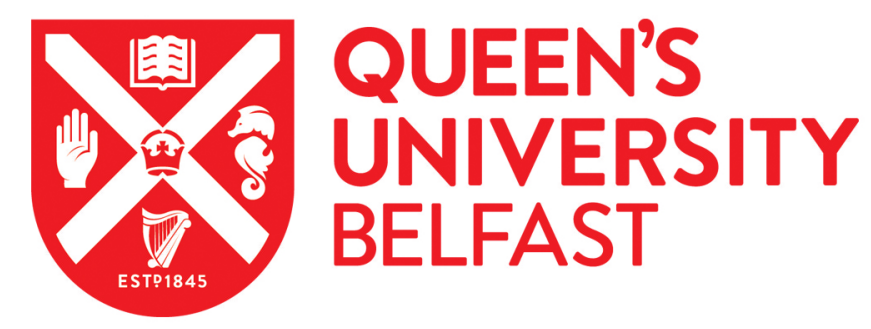

\title{
Aerospace Stiffened Panel Initial Sizing With Novel Skin Sub- Stiffening Features
}

Quinn, D., Murphy, A., \& Glazebrook, C. (2012). Aerospace Stiffened Panel Initial Sizing With Novel Skin SubStiffening Features. International Journal of Structural Stability and Dynamics, 12(5).

https://doi.org/10.1142/S0219455412500605

\section{Published in:}

International Journal of Structural Stability and Dynamics

\section{Document Version:}

Peer reviewed version

Queen's University Belfast - Research Portal:

Link to publication record in Queen's University Belfast Research Portal

\section{General rights}

Copyright for the publications made accessible via the Queen's University Belfast Research Portal is retained by the author(s) and / or other copyright owners and it is a condition of accessing these publications that users recognise and abide by the legal requirements associated with these rights.

Take down policy

The Research Portal is Queen's institutional repository that provides access to Queen's research output. Every effort has been made to ensure that content in the Research Portal does not infringe any person's rights, or applicable UK laws. If you discover content in the Research Portal that you believe breaches copyright or violates any law, please contact openaccess@qub.ac.uk. 


\title{
AEROSPACE STIFFENED PANEL INITIAL SIZING WITH NOVEL SKIN SUB-STIFFENING FEATURES
}

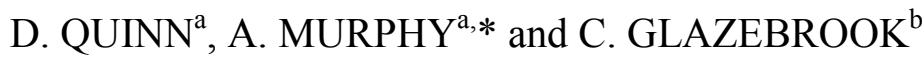 \\ ${ }^{a}$ School of Mechanical and Aerospace Engineering, Queen's University Belfast, \\ Ashby Building, Belfast, N. Ireland, U.K. BT9 5AH \\ ${ }^{b}$ Unité Aéronautique et Laminés Technique, Centre de Recherche de Voreppe \\ Centr'Alp, BP 27, 38341 Voreppe Cedex France
}

The introduction of skin sub-stiffening features has the potential to modify the local stability and fatigue crack growth performance of stiffened panels. Proposed herein is a method to enable initial static strength sizing of panels with such skin sub-stiffening features. The method uses bespoke skin buckling coefficients, automatically generated by Finite Element analysis, and thus limits the modification to the conventional aerospace panel initial sizing process. The approach is demonstrated herein and validated for prismatic sub-stiffening features. Moreover, examination of the generated buckling coefficient data illustrates the influence of skin sub-stiffening on buckling behaviour, with static strength increases typically corresponding to a reduction in the number of initial skin longitudinal buckle half-waves.

Keywords: Panel design, Panel initial sizing, Sub-stiffening, Integral stiffened panel.

*Corresponding author: Adrian Murphy (E-mail address: a.murphy@qub.ac.uk) 


\section{Introduction}

An aircraft stiffened panel is a highly efficient structure, designed to carry a range of loading while maintaining a specified level of damage tolerance. One of the advantages of the stiffened panel design is in permitting sections to locally buckle at load levels below the ultimate required capacity of the structure, potentially enabling additional weight savings. This beneficial characteristic is due to the stable postbuckling response of stiffened panels. The efficiency of stiffened panel structure is influenced by the interaction of materials, geometric design and assembly processes. For decades riveted built up metallic components have constituted the traditional aerospace panel structure. Such configurations, with associated manufacturing and fabrication details, have become highly refined and mature. It is therefore recognised to significantly reduce panel weight and cost further, concurrent improvements in materials, design and manufacturing processes are required.

Continual advances in the strength and damage tolerance characteristics of available metallic materials offers opportunity for increased stiffened panel working and limit stresses ${ }^{1,2}$. Developments of current and new manufacturing and assembly processes may offer further weight and cost savings. Improvements in high speed machining and extrusion capabilities indicate that widespread application of integral stiffened panel structures may become a feasible cost effective alternative to traditional built up panels, with savings associated with lower labour and tooling costs $^{3}$. Advanced joining techniques such as welding and robotic bonding may also contribute to reduced cost and weight ${ }^{4}$ in the assembly of multiple integral panels into wing or fuselage sub-sections. In addition, further weight savings are possible by embracing the potential of new manufacturing approaches to generate innovative stiffened panel geometric designs. The concept of skin sub-stiffening introduces local 
skin element structural features which transform the skin into a reinforced plate element within a panel and when designed correctly results in increased local fatigue or static strength performance without negatively impacting global panel behaviour ${ }^{5,6}$. Such panel design grants greater potential for geometric design tailoring to the local panel structural requirements and the new manufacturing methods enable the geometric complexity at acceptable cost.

\subsection{Crack containment features}

In conventional built-up panels, attached stiffeners act as crack arresters, restraining the propagation of fatigue crack growth. Integral panel structures, however, do not have natural breaks to act as crack arresters and therefore fatigue crack propagation through an integral structure is potentially faster. One of the first applications investigated of skin sub-stiffening has been to improve fatigue crack growth in integral structures with sub-stiffeners designed to act as "crack containment features". In experimental and numerical research the introduction of skin sub-stiffening has been demonstrated to significantly decrease fatigue crack growth ${ }^{6-8}$. The published results indicate that multiple regions of skin thickness variation, or crenulations, which are dimensionally wider than they are thicker, offer significant potential for improved panel life performance (see Figure 1).

\subsection{Buckling containment features}

Considering static strength, numerous plate ${ }^{9-11,18}$ and panel studies ${ }^{12-17,19-21}$ have demonstrated that non-uniform skin thickness can be used to tailor local stability behaviour. Quinn et al. ${ }^{14}$ experimentally and computationally demonstrates that the introduction of prismatic unflanged blade sub-stiffeners within panel skin bays (see 
Figure 1) can significantly modify initial stability behaviour and improve both the initial buckling, and post buckling collapse performance, thus using sub-stiffeners as panel "buckling containment features". The improvement in local panel stability is achieved by designing the skin plus sub-stiffeners to initially buckle as a combined unit between the much larger primary longitudinal and transverse stiffeners. This behaviour is dissimilar to panel performance improvement through the introduction of variable primary stiffener size ${ }^{12,13}$. In the case of variable primary stiffener size, the inclusion of smaller stiffeners between larger stiffeners has demonstrated mass savings and more robust longitudinal and transverse stiffener pitch optimums. Within these studies, the smaller stiffeners enforce skin buckling node lines and thus represent typical panel stability behaviour.

\subsection{Available analysis methods}

With regard to the design and analysis of sub-stiffened panel structure, the reviewed literature has demonstrated the ability to numerically predict fatigue crack growth and stability behaviour with a high degree of accuracy. A number of studies have validated, using bespoke experimental test data, the application of finite element analysis with shell element idealisations ${ }^{5,6,14,21}$ for this task. However, the application of finite element analysis for initial sizing is not practical given the associated modelling and computational expense.

\subsection{Research objectives}

Thus to enable the use of skin sub-stiffening features in industrial design 'efficient' methods are required for initial sizing of panel structures. Given the importance of static strength in initial panel sizing, the objective herein is to develop an 'efficient' 
method to enable static strength design of panels with skin sub-stiffening features. To this end the following section briefly outlines the conventional panel initial sizing process, which will be adapted to accommodate the complexities of sub-stiffened panel behaviour. An overview of the proposed methodology is then presented before an exemplar demonstration of its application to two basic sub-stiffening configurations. The details of the generated design data are then presented and discussed, including appraisal of the accuracy of the method against experimental test data.

\section{Conventional Aerospace Panel Design}

Given the practice of allowing the skin elements between stiffeners to buckle at a percentage of the ultimate load, the ability to predict the local buckling, post-buckling and failure behaviour of stiffened panel designs is essential. To this end, a stiffened panel structure can be idealised as a series of plate and column elements. Prediction of panel behaviour and performance is thus achieved using plate and column stability theory. Typically, a post buckled design experiences initial buckling as a local instability of the plate elements such as the skin bays between the lateral and longitudinal stiffeners, and panel failure as an overall instability of stiffener elements between the lateral and longitudinal stiffener intersects. Conventional aerospace initial sizing procedures evaluate and interrogate the various instability modes of the panel elements to predict panel static behaviour and performance. The procedure described in this section replicate the aerospace industrial methods for the analysis of conventional stiffened panels. 
Stiffened panel skin bays are typically thin plate elements with degrees of support on all sides. Buckling is typically a short wavelength mode, where the wavelength is of the approximate order of the lateral stiffener pitch. The critical buckling stress of such a plate is defined by

$$
\sigma_{C R}=\frac{K \pi^{2} E_{t}}{12\left(1-v^{2}\right)}\left(\frac{t}{b}\right)^{2}
$$

where $t$ is the plate thickness, $b$ is the plate width between edge support conditions, $K$ is the buckling coefficient and $E_{t}$ is the tangent modulus to account for material plasticity. The non-dimensional buckling coefficients can be obtained from a number of standard reference sources ${ }^{22-25}$. For all cases, selection of a suitable buckling coefficient is based on plate aspect ratio and edge support conditions.

Despite the occurrence of initial buckling, portions of plate adjacent to stiffeners are stabilised and are considered to act as part of the effective post-buckled stiffener column. According to Von Karman ${ }^{23}$, the width of the post-buckled effective plate is defined as:

$$
b_{\text {Effective }}=b \sqrt{\frac{\sigma_{\text {Buckle }}}{\sigma_{\text {Stiffener }}}}
$$

where $\sigma_{\text {Buckle }}$ is the stress at which the plate element initially buckles and $\sigma_{\text {Stiffener }}$ is the stress at the plate edge when the effective post-buckled stiffener column fails.

Failure of an effective post-buckled stiffener column may be determined using, for example, the secant formula that is given by 


$$
\sigma_{\text {Max }}=\sigma_{\text {Column }}\left[1+\frac{\text { ey }}{\rho^{2}} \operatorname{Sec}\left[\frac{L^{\prime}}{2 \rho} \sqrt{\frac{\sigma_{\text {Column }}}{E_{t}}}\right]\right]
$$

Here the critical stress, $\sigma_{\text {Max }}$, can be based on a local material yield or a local stiffener element instability value.

Further details on typical aerospace post-buckling failure analysis for the various potential buckling mode forms of stiffened panels may be found in references 23,24 and 26.

In summary, current industrial initial sizing processes for conventional stiffened panels rely on simple plate and column analysis equations. However, for novel panel skin geometries, designed to improve local stability or fatigue crack growth performance, the application of conventional plate equations is limited to designs where the skin sub-stiffeners are known to behave as conventional stiffeners i.e. enforcing skin buckling node lines. When the skin sub-stiffeners induce, either intentionally or not, the initial buckling of the skin and sub-stiffeners as a combined unit between the much larger primary stiffeners, the current initial sizing methods are no longer appropriate.

\section{Methodology}

\subsection{Analysis modifications}

Considering practical industrial application, the introduction of panel sub-stiffening should require minimal deviation from existing verified design practice. Thus it is proposed that the sub-stiffened panel analysis method is a variation on the conventional skin stability calculation [Eq. (1)], where the conventional plate buckling coefficients are replaced with numerically generated buckling coefficients 
$\left(\mathrm{K}^{\prime}\right)$ representing the sub-stiffened skin stability behaviour, and the plate thickness replaced with a smeared thickness value $\left(t_{\text {smeared }}\right)$ representing the sub-stiffened skin geometry, i.e.

$$
\sigma_{C R}=\frac{K^{\prime} \pi^{2} E_{t}}{12\left(1-v^{2}\right)}\left(\frac{t_{\text {smeared }}}{b_{\text {stiffener }}}\right)^{2}
$$

The use of the Finite Element Method, to generate buckling coefficients permits a very flexible way to consider a vast range of sub-stiffener designs and boundary conditions with a single approach. Buckling coefficients could also be generated very efficiently using the Finite Strip Method or general plate stability theory (removing a number of assumptions used in the development of the standard flat plate buckling coefficients $^{22}$ ). Finite Strip programs such as PANDA2, PASCO, VIPASA and VICONOPT can consider (separately) a range of possible buckling mode halfwavelengths and so can determine the critical buckling mode, losing only a small proportion of their computational advantage. A more serious drawback comes with applying a general plate stability theory approach, where there is the requirement to know or assume the buckling mode a priori. Given the importance of the form of initial buckling to plate sub-stiffening performance this introduces a major challenge when considering a range of sub-stiffener designs and boundary conditions.

Considering the post buckling and collapse performance of a panel with substiffened skin elements, it is proposed to apply the Von Karmen definition of postbuckled effective width, thus assuming that sub-stiffened skin elements exhibit postbuckled stress distributions which are not significantly different in form to that of a plate of uniform thickness. The accuracy of this assumption will be examined herein. 
The existing conventional stiffener column instability calculations can then be employed as normal.

\subsection{Implementation}

The following sub-sections offer a three step process through which buckling coefficients can be created for individual sub-stiffened skin configurations.

\subsubsection{Selection of sub-stiffening design space}

Sub-stiffening introduces an increased number of design variables, with each variable potentially having a different influence on stability behaviour, thus a process is required to organise and manage the increased number of design variables. To this end a Design of Experiments (DOE) ${ }^{27}$ approach is proposed, initially to rank the impact of each design variable on the initial buckling behaviour, and develop an understanding of design variable interaction and the potential structural performance range of the sub-stiffening configuration. Clearly this is a most important process and requires careful consideration of the individual sub-stiffening configuration design intent, and the targeted structural application and manufacturing processes.

The output of this initial DOE analysis will be a definition of the design variables (and their range) which will function as attributes to extract buckling coefficients from a generated library. Of worthy note is the target to produce buckling coefficient libraries which reference non-dimensional geometric ratios, such as plate aspect ratio, sub-stiffener height or thickness ratio, imitating standard buckling coefficient data ${ }^{22-}$ 25

\subsubsection{Generation of buckling coefficient library}


Once the appropriate design space has been identified the raw data required to build a buckling coefficient library may be created. For the selected analysis technique verification and ideally experimental validation for a number of key cases across the design space is required.

Herein the use of the Finite Element Method is demonstrated and thus it is important to stress the robust selection and verification of modelling and solution parameters. The choice of idealisation philosophy is highly dependent on the anticipated behaviour of the sub-stiffening configuration, as the structural idealisation must be capable of accurately representing this. The proposed sub-stiffening configurations which motivate this work, outlined in Sections 1.1 and 1.2, are potentially susceptible to local and global buckling modes. In order to effectively represent the buckling modes it is suggested that the structure be idealised as an assemblage of shell elements ${ }^{28,29}$. Of key importance is the mesh convergence study for determining the minimum mesh density required to accurately represent the range of buckling behaviours associated with the range of geometry within the defined design space.

Again, considering the proposed sub-stiffening configurations which motivate this work, a linear elastic material model plus an eigenvalue analysis is advocated to determine the buckling behaviour of the structure. The concept of eigenvalue buckling prediction is to investigate singularities in a linear perturbation of the structure's stiffness matrix, obtaining estimates of the critical load at which the response of the structure will bifurcate (buckle). The predicted behaviour will only be valid when the linear perturbation is a realistic reflection of the structure's response before buckling. In the case of any plastic material behaviour this could be considered within Eq. (4), through the material tangent modulus, as is done within the conventional panel 
analysis method. This approach considers non-linear material behaviour but still assumes small linear geometric deformations before initial buckling.

Having verified the analysis procedure for the selected sub-stiffening configuration and design space, the process of creating models, running analysis and postprocessing results requires automation. For the two case-studies presented herein an assemblage of in-house and Commercial Off The Shelf (COTS) Finite Element programmes have been used to create a tool which enables the user to easily define the sub-stiffening configuration and its design space. The tool in a batch processing mode automatically generates and executes the required simulations and assembles the buckling coefficient library. The coefficients are calculated by

$$
K^{\prime}=\frac{12\left(1-v^{2}\right) \sigma_{\text {Buckle }}}{E \pi^{2}}\left(\frac{b_{\text {plate }}}{t_{\text {smeared }}}\right)^{2}
$$

where $\sigma_{\text {Buckle }}$ is the buckling stress predicted by the eigenvalue analysis. In addition to the coefficient magnitudes, the buckling mode is also captured and stored.

\subsubsection{Integration within conventional panel sizing methods}

Once a buckling coefficient library has been created and verified, it must be possible to integrate this data within the conventional industrial procedures for panel sizing. To demonstrate such integration a panel sizing tool has been created, incorporating the conventional analysis procedures, summarised in Section 2 and detailed in references 23,24 and 26 .

\subsection{Sub-stiffening configuration case studies}


Having presented a generic overview of the proposed methodology a number of casestudies for two sub-stiffening configurations are presented to demonstrate application. Both configurations, i.e. prismatic unflanged blade and prismatic crenulation, represent concepts highlighted in the literature, Section 1.1 and 1.2.

\subsubsection{Prismatic blade case studies}

Figure 1 illustrates skin sub-stiffening with prismatic blades. These sub-stiffening features are similar in form to conventional primary blade stiffeners, but geometrically smaller. Based on the reviewed literature three generic blade substiffening configurations are examined:

CASE PB1 Equally spaced blades of uniform height,

CASE PB2 Equally spaced blades with a height distribution defined by the function in the following equation

$$
\begin{aligned}
& \mathrm{y}=\left(\frac{\mathrm{h}_{\text {Min }}}{2}-\frac{\mathrm{h}_{\text {Max }}}{2}\right)+\left(\frac{\mathrm{h}_{\text {Min }}-\mathrm{h}_{\text {Max }}}{2}\right) \cos \left(\frac{\pi \mathrm{x}}{\varphi \mathrm{b}}\right) \\
& \text { in which } \varphi=2 .
\end{aligned}
$$

$\underline{\text { CASE PB3 }}$ Equally spaced blades with height distribution defined by the function in Eq. (6), in which $\varphi=4$.

A pictorial illustration of each case study configuration is presented along with the analysis results within the following paper section. The function in Eq. (6) enables the definition of potentially advantageous blade and crenulation sub-stiffener height distributions, enabling the tailoring of out-of-plane bending stiffness to reflect typical buckling mode forms and improve buckling resistance.

\subsubsection{Prismatic crenulation case studies}


Figure 1 illustrates skin sub-stiffening with prismatic crenulations. These features are rectangular "pads", dimensionally wider than they are thick, strategically located along the skin width. Based on the reviewed literature two generic crenulation configurations are examined:

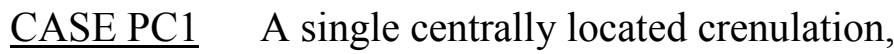

$\underline{\text { CASE PC2 }}$ One central and two edge crenulations.

The case studies will focus on fuselage applications, with critical compression loading (of the order of $400 \mathrm{~N} / \mathrm{mm}$ ), and a targeted initial skin buckling to ultimate strength performance ratio of between $1 / 3$ and $2 / 3$. This corresponds with the design intent of the configurations being considered and the available experimental data for validation. The coefficient libraries are generated considering the manufacturing method of panel machining from plate, and thus design space geometric increments equate to typical aerospace machining thickness and height steps.

\section{Results and Discussion}

The buckling coefficient libraries for the prismatic blade configurations are first presented and discussed, before being used to validate the modifications to the conventional sizing methods. Having validated the analysis modifications integration of the coefficient library within a conventional panel sizing tool is demonstrated. The demonstration examines minimum mass designs, with and without skin sub-stiffening, for a range of primary stiffener pitches.

\subsection{Prismatic blade case studies}

\subsubsection{Preliminary design space analysis}


A single DOE analysis is undertaken for the three prismatic blade case studies. Using a fractional factorial DOE method all design variables are treated as discrete and an orthogonal array is used to define which combinations of variables are simulated. Table 1 outlines the design variables along with the variable upper and lower limits appropriate for the selected loading and manufacturing methods. In this case a L8 two-level orthogonal array ${ }^{27}$ is used, resulting in a total of eight simulations. Once the simulations are completed, an 'Analysis of Means' is carried out to identify the influence of each design variable, Table 1A and an 'Analysis of Variance' to determine the relative contributions of the design variable, Table 1B. The following overall observations can be made based on the DOE results presented in Table 1:

- within the studied design space, blade height has the most dominant influence on stability and the lowest impact of the dimensional variables on mass.

- the remaining dimensional variables (skin and blade thickness) and the number of blades per bay make a notable contribution to both stability and mass.

- within the studied design space the analysis indicates that the examined spatial distribution of the blades has a limited influence on stability.

Thus the buckling coefficient libraries will be generated around two key design variables:

- blade height ratio (ratio of blade height to plate width), and,

- blade thickness ratio (ratio of blade thickness to skin thickness, where a thickness ratio of zero corresponds to an un-stiffened skin).

\subsubsection{Buckling coefficient library}

\subsubsection{CASE PBI}


In order to demonstrate the generated buckling coefficient data in a clear and relevant form a sample of the total available data is presented. To allow immediate comparison of the influence of the design variables, the presented data sample is restricted to equal material volumes (skin plus sub-stiffeners) and a single aspect ratio and boundary condition composition. Figure 2 thus presents data for a skin element of aspect ratio 3.5 with a sub-stiffening configuration of ten blades of uniform height and thickness. The skin is simply supported on all edges and the sub-stiffener edges are supported with material constraints, representing continuous sub-stiffening fore and aft of the section.

On examining the presented data sample in Figure 2 the most significant change in performance can be attributed to increasing blade height ratio. Increasing the blade thickness ratio initially increases the buckling coefficient magnitude, with the increase reducing in magnitude beyond a ratio of 0.5 . With regards skin buckling form, increased buckling coefficient magnitude corresponds to a reduction in the number of longitudinal buckle half-waves. The presented sample indicates potentially significant increases in buckling coefficients; however it is important to note that buckling coefficients do not include the influence of material plasticity.

\subsubsection{CASE PB2}

Figure 3 presents a sample of the generated buckling coefficient data, as before the sample is for equal material volume designs of a skin element with an aspect ratio of 3.5 and simply supported skin edges, and material constrained sub-stiffener edges. The general trends are similar to that of the uniform height configuration. However, due to the variable blade height distribution the out-of-plane bending stiffness at the skin centre will be greater than that of a uniform height configuration, explaining the 
higher buckling coefficients available. Increased blade height and thickness ratios also correspond to a reduction in the number of longitudinal buckle half-waves, with the maximum observed buckling coefficients again coinciding with a single longitudinal half wave.

The sample buckling coefficient data also demonstrates a case where buckling of the sub-stiffening blades is observed, violating the design intend of the sub-stiffening configuration. This further highlights the importance of understanding the limiting or extreme stability behaviour when developing skin sub-stiffening configurations and appropriate Finite Element meshes for their analysis.

\subsubsection{CASE PB3}

Figure 4 presents a sample of the generated buckling coefficient data, again for a skin element with an aspect ratio of 3.5. Again the observed behaviour is similar to the previous configuration with performance gains corresponding to increasing blade height and thickness ratios. Examining Figure 4, the most significant changes in buckling coefficient magnitude coincide with variation in sub-stiffener blade height ratio. In this case extreme blade thickness $(\geq 1.5)$ and height ratios $(\geq 0.04)$ can lead to less optimal buckling behaviour and marginally lower buckling coefficients.

\subsubsection{Summary}

Increasing the out-of-plane bending stiffness at the skin centre can significantly increase the initial buckling resistance of a blade sub-stiffened skin element, with the increased performance typically accompanied with a reduction in the number of initial longitudinal buckle half-waves. With regards to blade height distributions, varying blade height across the skin can yield potentially greater buckling coefficients and 
thus performance gains. It is also observed that increasing blade height towards the skin edge is not particularly beneficial. The skin behaviour observed may be categorised into two forms. In the first the skin plus sub-stiffeners buckle as a unit, this form of instability is of particular interest herein. The second form of instability involves sub-stiffeners buckling with the skin remaining in-plane and stable, with this behaviour defining the limits of the particular configuration's design space.

\subsubsection{Analysis method validation}

The data used to validate the developed methodology is taken from experimental and numerical studies presented in Quinn et al. ${ }^{14}$. The experimental specimen was manufactured by machining from plate and consisted of three primary blade stiffeners, two central skin bays and two edge skin bays all strengthened with equally spaced blade sub-stiffeners of uniform height (see Figure 5). The material used was aluminium alloy 2024-T351 and the specimen was designed for pure compression loading. The sub-stiffening configuration resulted in a blade height ratio of 0.055 and a blade thickness ratio of 0.93 . The specimens were tested in a $500 \mathrm{kN}$ capacity hydraulic testing machine. A reinforced epoxy resin base was cast on to each specimen loading end, producing clamped boundary conditions; the specimens unloaded edges were left unrestrained during test. Each specimen was strain gauged with gauge locations selected to enable the definition of initial specimen buckling and post-buckling collapse behaviour. Specimen end-shortening was measured during test using two calibrated displacement transducers. To capture skin buckling behaviour during test, a three-dimensional Digital Image Correlation (DIC) system was used. The specimens were loaded monotonically, in displacement control, at a rate of 0.40 mm per minute until failure occurred. Load, deflection, strain data and DIC images 
were recorded at 2-second intervals during test. The prediction of panel performance was carried out with the developed sizing tool as outlined in Section 3. Table 2 presents the critical panel loads and modes from the experimental and finite element studies, in addition to the predicted loads and modes produced using the modified sub-stiffening design method. Figure 5 presents the observed experimental initial specimen buckling behaviour along with the predicted skin-bay mode shape. The nonsymmetric mode shape in the longitudinal direction displayed by the specimen skin is believed to relate to the specimen's initial geometric imperfection.

By examining initial buckling, the modified analysis method over-predicts both the experimental and numerical buckling loads by $+7.1 \%$ and $+4.0 \%$ respectively (see Table 2). The predicted critical buckling mode form of a single half wave along the length of the skin bay predicted by the modified analysis method is in agreement with the experimental and finite element data as shown in Figure 5. The modified analysis method predicts panel collapse to occur at a load $2.16 \%$ lower than that experimentally measured, and $2.84 \%$ higher than that predicted by the non-linear Finite Element analysis. For this particular design case, the developed sub-stiffening design methodology predicted sub-stiffened panel performance with a relatively high degree of accuracy against the published experimental data.

Examining the assumption that sub-stiffened skin elements exhibit post-buckled longitudinal stress distributions which are not significantly different in form to that of a uniform flat plate - Figure 6 presents the measured and Finite Element predicted pre and post buckled out-of-plane displacements, surface strains and mid-plane stresses along the longitudinal centre line of the validation specimen. No mid-plane experimental strain data is available, however the numerically predicted displacement and surface strain distribution is in close agreement with the experimental data with 
regards to magnitude and trend, indicating that the numerically predicted mid-plane stress distributions are representative of the experimental validation specimen. Considering these mid-plane stress distributions, the transition from a relatively linear pre-buckled stress distribution to a sinusoidal post-buckled distribution with higher stresses at the skin bay edges/primary stiffeners is typical of a conventional uniform flat skin bay, suggesting that the Von Karman effective width assumption is a good approximation for the sub-stiffening configuration under investigation.

\subsubsection{Panel design study - primary stiffener pitch}

Considering the improved initial buckling performance associated with prismatic blade sub-stiffening a design study has been carried out to determine if these improvements can be translated into lighter or more robust designs. The validated analysis method is used to size a fuselage panel with a target failure load of 400 $\mathrm{N} / \mathrm{mm}$ and a target initial buckle load of above $132 \mathrm{~N} / \mathrm{mm}$. To focus the assessment to skin sub-stiffening the primary stiffener geometry is fixed for both the conventional and sub-stiffened designs. Figure 7 presents the minimum mass designs for a range of primary stiffener pitches.

With regards to the design of a conventional panel, reducing primary stiffener pitch consistently generates a lighter design, with the mass optimal design effectively defined by the minimum stiffener pitch that is acceptable for manufacture. Considering the sub-stiffened panels, the minimum mass designs are less sensitive to the primary stiffener pitch. The increased design robustness attributed to the substiffened panels is also reflected in the predicted mass savings observed. It is worth noting that including the primary stiffener geometry within the optimisation studies would increase the number of design variables available within both the conventional 
and sub-stiffened cases and thus may impact on the magnitude between the optimised panel masses.

\subsection{Prismatic crenulations}

Having validated the proposed design process with sub-stiffening blades this section presents and discusses the prismatic crenulation case studies. Additionally a sample coefficient set is presented against plate aspect ratio enabling direct comparison between flat and sub-stiffened plate coefficient magnitudes.

\subsubsection{Preliminary design space analysis}

Table 3 outlines the potential design variables for prismatic crenulation configurations. Again a fractional factorial DOE method is used to examine the design variables and the following overall observations can be made based on the "Analysis of Means', Table 3A, and the 'Analysis of Variance', Table 3B results:

- alignment of the crenulated cross section to the loading direction has the most dominant influence on stability. Within the studied design space it can be seen that the effect of aligning crenulations perpendicular to the primary loading axis has no stability benefit.

- skin thickness and crenulation width have similar influence on stability and also have the most influence on mass.

- with regards to the impact of crenulation thickness on stability, it is important to note that the interaction of crenulation thickness with skin thickness is more influential than the crenulation thickness alone. 
Thus the buckling coefficient libraries will be generated around two key design variables:

- crenulation width ratio (ratio of crenulation width to plate width),

- crenulation thickness ratio (ratio of crenulated section thickness to skin thickness, where a thickness ratio of one corresponds to an un-stiffened skin).

\subsubsection{Buckling coefficient library}

\subsubsection{CASE PC1}

Following the previous format, Figure 8 presents sample buckling coefficient data from the library generated for the single centrally located crenulation configuration. For a fixed crenulation width ratio, increasing the crenulation thickness ratio leads to larger buckling coefficients. However, for a fixed crenulation thickness ratio, increasing the crenulation width ratio leads to decreasing buckling coefficients. This second relationship is a consequence of presenting equivalent material volume coefficient data and thus increased crenulation width necessarily leads to reduced skin and crenulation thickness. Thus Section 4.2.4 demonstrates a more traditional and unconstrained method of presenting coefficient data. By examining the form of initial buckling, as with the previous blade results, decreased numbers of longitudinal halfwaves correspond to increased buckling coefficients and vice versa.

\subsubsection{CASE PC2}

Figure 9 presents sample buckling coefficient data for the sub-stiffened configuration with edge and a central crenulation. Examining the data indicates that, for this particular configuration, increased buckling coefficients correspond to increasing crenulation thickness and width ratios, and an associated reduction in the number of 
initial buckle longitudinal half-waves. From Figure 9, it is clear that the crenulation thickness ratio demonstrates greater influence on buckling coefficient magnitude than the width ratio.

\subsubsection{Summary}

In general the crenulated library data behaviour mirrors the blades sub-stiffener configurations, with increasing out-of-plane bending stiffness of the structure, increasing buckling coefficient magnitudes and reducing the number of initial buckle longitudinal half-waves. Considering the two crenulated concepts studied, the combination of edge and central crenulations offers the highest performance gains within the design space.

Having examined both blade and crenulation sub-stiffening it is possible to compare the stability performance of the two configurations. For a fixed aspect ratio and total mass (plate plus sub-stiffeners), blade sub-stiffening generally enables greater buckling coefficient magnitudes. However it is important to note that blade sub-stiffening has been proposed to control local stability whereas crenulation substiffening has been proposed to control fatigue crack growth, thus a simple comparison of achievable buckling coefficients is only part of a configurations performance attributes.

\subsubsection{Aspect ratio}

The buckling coefficient data presented in the previous sections is focused on a fixed skin element aspect ratio of 3.5. Figure 10 presents buckling coefficient data for a crenulated sub-stiffened skin with a fixed crenulation thickness and width ratio, but varying skin element aspect ratio. The behaviour observed is similar to that of an un- 
stiffened plate, also presented in Figure 10, with an almost exponential relationship between the aspect ratio and the buckling coefficient. For the particular design configurations studied, the performance converges towards a level that is approximately $50 \%$ higher than that of an un-stiffened plate. With regards to the critical buckling mode form, the number of longitudinal half-waves for the crenulated design is consistently lower than that of an equivalent un-stiffened plate.

\section{Conclusions}

Proposed herein is a method to enable static strength initial sizing of panels with skin sub-stiffening features. Through automated Finite Element analysis bespoke local skin buckling coefficients can be generated for various sub-stiffening configurations and local geometry. The proposed methodology limits the required modifications to the conventional aerospace design and analysis processes, and is herein demonstrated and validated for prismatic sub-stiffening features. In addition to providing sub-stiffened skin buckling coefficient data, the process of generating data also offered the opportunity to further understand sub-stiffened panel stability behaviour. General trends indicate that increasing inertia at the centre of the skin element can yield improved performance, with performance increases typically corresponding to a reduction in the number of longitudinal half-waves, with optimal performance occurring when the sub-stiffened skin element behaves as a unit, with buckling corresponding to overall out-of-plane displacement of the skin and sub-stiffening features in a single longitudinal half-wave. The proposed Finite Element based approach may be applied to a large range of sub-stiffening concepts to produce local skin buckling coefficients and thus enable panel static strength design. 


\section{Acknowledgements}

The authors gratefully acknowledge the technical and financial support of Alcan CRV, Voreppe, France.

\section{References}

1. P. Lequeu, A. Danielou and F. Eberl, Latest Generation of Al-Li Plate Alloys Developed by Alcan Aerospace, Proc. 18th Advanced Aerospace Materials \& Processes Conf. and Expo., AeroMat, Baltimore (2007).

2. R. J. Bucci, Advanced Metallic and Hybrid Structural Concepts: Tailorable solutions to meet the demanding performance/affordability requirements of tomorrow's aircraft, Proc. Aircraft Structural Integrity Program Conf., ASIP, San Antonio (2006).

3. J. Munroe, K. Wilkins, M. and Gruber, Integral Airframe Structures (IAS) Validated feasibility study of integrally stiffened metallic fuselage panels for reducing manufacturing costs, Tech. rep. NASA/CR-2000-209337, NASA, Langley Research Center (2000).

4. E. Schubert, M. Klassen, I. Zerner, C. Walz and G. Sepold, Light-weight structures produced by laser beam joining for future applications in automobile and aerospace industry, J. Mater. Process. Technol. 115 (2001) 2-8.

5. A. Murphy, D. Quinn, P. Mawhinney, M. Ozakça and S. van der Veen, Tailoring static strength performance of metallic stiffened panels by selective local sub-stiffening, Proc. 47th AIAA/ASME/ASCE/AHS/ASC Structures, Structural Dynamics, and Materials Conf., Newport, Rhode Island (2006). 
6. J. C. Ehrström, S. Van der Veen, S. Arsène and R. Muzzolini, Improving damage tolerance of integrally machined panels, Proc. 23rd Symposium of International Committee on Aeronautical Fatigue, ICAF, Hamburg (2005).

7. R. Muzzolini and J. C. Ehrstrom, Damage tolerance of integral structures with crack retardation features. Proc. 15th Advanced Aerospace Materials \& Processes Conf. and Expo., AeroMat, Seattle (2004).

8. M. Boscolo, G. Allegri and X. Zhang, Design and modeling of selective reinforcements for integral aircraft structures, AIAA J. 46 (2008).

9. M. Eisenberger and A. Alexandrov, Buckling loads of variable thickness thin isotropic plates, J. Thin-walled Struct. 41 (2003) 871-889.

10. J. Petrisic, F. Kosel and B. Bremec, Buckling of plates with strengthenings, $J$. Thin-walled Struct. 44 (2006) 334-343.

11. A. R. Rahai, M. M. Alinia and S. Kazemi, Buckling analysis of stepped plates using modified buckling mode shapes, J. Thin-walled Struct. 46 (2008) 484493.

12. D. Bushnell and C. Rankin, Optimum design of stiffened panels with substiffeners, Proc. 46th AIAA/ASME/ASCE/AHS/ASC Structures, Structural Dynamics \& Materials Conf., Austin, Texas (2005).

13. A. Watson, C. A. Featherston and D. Kennedy, Optimization of postbuckled stiffened panels with multiple stiffener sizes, Proc. 48th AIAA/ASME/ASCE/AHS/ASC Structures, Structural Dynamics, and Materials Conf., Honolulu, Hawaii (2007).

14. D. Quinn, A. Murphy, W. McEwan and F. Lemaitre, Stiffened panel stability behaviour and performance gains with plate prismatic sub-stiffening, J. Thinwalled Struct. 47 (2009) 1457-1468. 
15. Anonymous, Isogrid Design Handbook, Tech. rep. NASA/CR-124075, NASA (1973).

16. C. Collier, P. Yarrington and B. Van West, Composite, grid-stiffened panel design for post buckling using hypersizer, Proc. $43 \mathrm{rd}$ AIAA/ASME/ASCE/AHS/ASC Structures, Structural Dynamics, and Materials Conf., Denver, Colorado (2002).

17. D. J. Baker and C. Kassapoglou, Post buckled composite panels for helicopter fuselages: Design, analysis, fabrication and testing, Proc. American Helicopter Society, Hampton Roads Chapter, Structures Specialists Meeting, Williamsburg, Virginia (2001).

18. C. B.York, Buckling interaction in regular arrays of rigidly supported composite laminated plates with orthogrid, isogrid and anisogrid planform, J. Am. Helicopter Soc. 52 (2007) 343-359.

19. R. Kapania, J. Li and H. Kapoor, Optimal design of unitized panels with curvilinear stiffeners, Proc. 5th AIAA Aviation Technology, Integration and Operations Conf., Arlington, Virginia (2005).

20. M. Ozakca, A. Murphy and S. van der Veen, Buckling and post-buckling of substiffened or locally tailored aluminium panels, Proc. 25th International Congress of the Aeronautical Sciences, ICAS, Hamburg (2006).

21. Quinn D., Murphy A., McEwan W. and Lemaitre F. Non-prismatic substiffening for stiffened panel plates-Stability behaviour and performance gains, J. Thin-walled Struct. 48 (2010) 401-413.

22. S. P. Timoshenko and J. M. Gere, Theory of Elastic Stability (McGraw-Hill Book Company Inc., New York, 1961). 
23. E. F. Bruhn, Analysis and Design of Flight Vehicle Structures (Tri-State Offset Company, Cincinnati, 1973).

24. Anonymous, ESDU structures sub-series (ESDU International Ltd, London, 2011).

25. P. S. Bulson, The Stability of Flat Plates (Chatto \& Windus, London, 1970).

26. Anonymous, NASA Astronautics Structures Manual - Volume 3 (NASA, Washington, 1961).

27. W. Yuin and A. Wu, Taguchi Methods for Robust Design (American Society of Mechanical Engineers, ASME Press, 2000).

28. C. Lynch, A. Murphy, M. Price and A. Gibson, The computational postbuckling analysis of fuselage stiffened panels loaded in compression, J. Thinwalled Struct. 42 (2004) 1445-1464.

29. M. M. Domb, W. G. Elliott and B. R. Leigh, Modelling of stiffener crippling phenomena using finite element analysis, Can. Aeronaut. Space J. 44 (1998) $256-262$. 

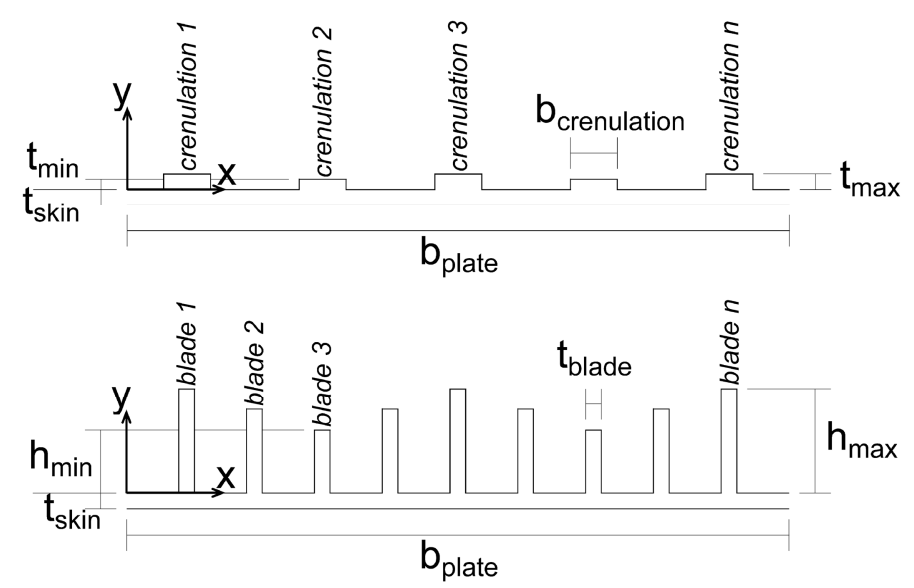

Figure 1 Prismatic sub-stiffening configurations.

\begin{tabular}{|c|c|c|c|c|c|c|}
\hline$t_{\text {skin }}$ & $y$ & & $t_{\text {blade }}$ & $\mathrm{h}_{\text {blade }}$ & $\begin{array}{l}\text { Blade Height } \\
\text { Blade Thickness }\end{array}$ & $\begin{array}{l}\text { atio }=\frac{\mathrm{h}_{\text {blade }}}{\mathrm{b}_{\text {plate }}} \\
\text { atio }=\frac{t_{\text {blade }}}{t_{\text {skin }}}\end{array}$ \\
\hline & & \multicolumn{5}{|c|}{ Blade Thickness Ratio } \\
\hline & & 0.0 & 0.5 & 1.0 & 1.5 & 2.0 \\
\hline \multirow{4}{*}{ 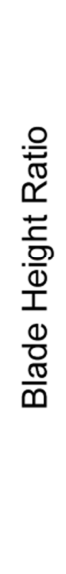 } & 0.03 & \multirow{4}{*}{$\begin{array}{c}\mathrm{m}=4, \mathrm{n}=1 \\
\mathrm{k}=4.0\end{array}$} & $\begin{array}{c}m=2, n=1 \\
k=6.34\end{array}$ & $\begin{array}{c}m=1, n=1 \\
k=7.3\end{array}$ & $\begin{array}{c}m=1, n=1 \\
k=7.1\end{array}$ & $\begin{array}{c}m=1, n=1 \\
k=6.9\end{array}$ \\
\hline & 0.04 & & $\begin{array}{c}m=1, n=1 \\
k=9.4\end{array}$ & $\begin{array}{c}\mathrm{m}=1, \mathrm{n}=1 \\
\mathrm{k}=9.9\end{array}$ & $\begin{array}{c}\mathrm{m}=1, \mathrm{n}=1 \\
\mathrm{k}=10.1\end{array}$ & $\begin{array}{c}m=1, n=1 \\
k=10.2\end{array}$ \\
\hline & 0.05 & & $\begin{array}{c}m=1, n=1 \\
k=12.6\end{array}$ & $\begin{array}{c}\mathrm{m}=1, \mathrm{n}=1 \\
\mathrm{k}=14.3\end{array}$ & $\begin{array}{c}m=1, n=1 \\
k=15.1\end{array}$ & $\begin{array}{c}m=1, n=1 \\
k=15.6\end{array}$ \\
\hline & 0.06 & & $\begin{array}{c}m=1, n=1 \\
k=17.3\end{array}$ & $\begin{array}{c}m=1, n=1 \\
k=20.6\end{array}$ & $\begin{array}{c}m=1, n=1 \\
k=22.1\end{array}$ & $\begin{array}{l}m=1, n=1 \\
k=22.8\end{array}$ \\
\hline
\end{tabular}

Figure 2 Sample buckling coefficient data for CASE PB1 (ten sub-stiffening blades, uniform blade thickness, aspect ratio 3.5, simply supported skin edges, and material constrained sub-stiffener edges). 


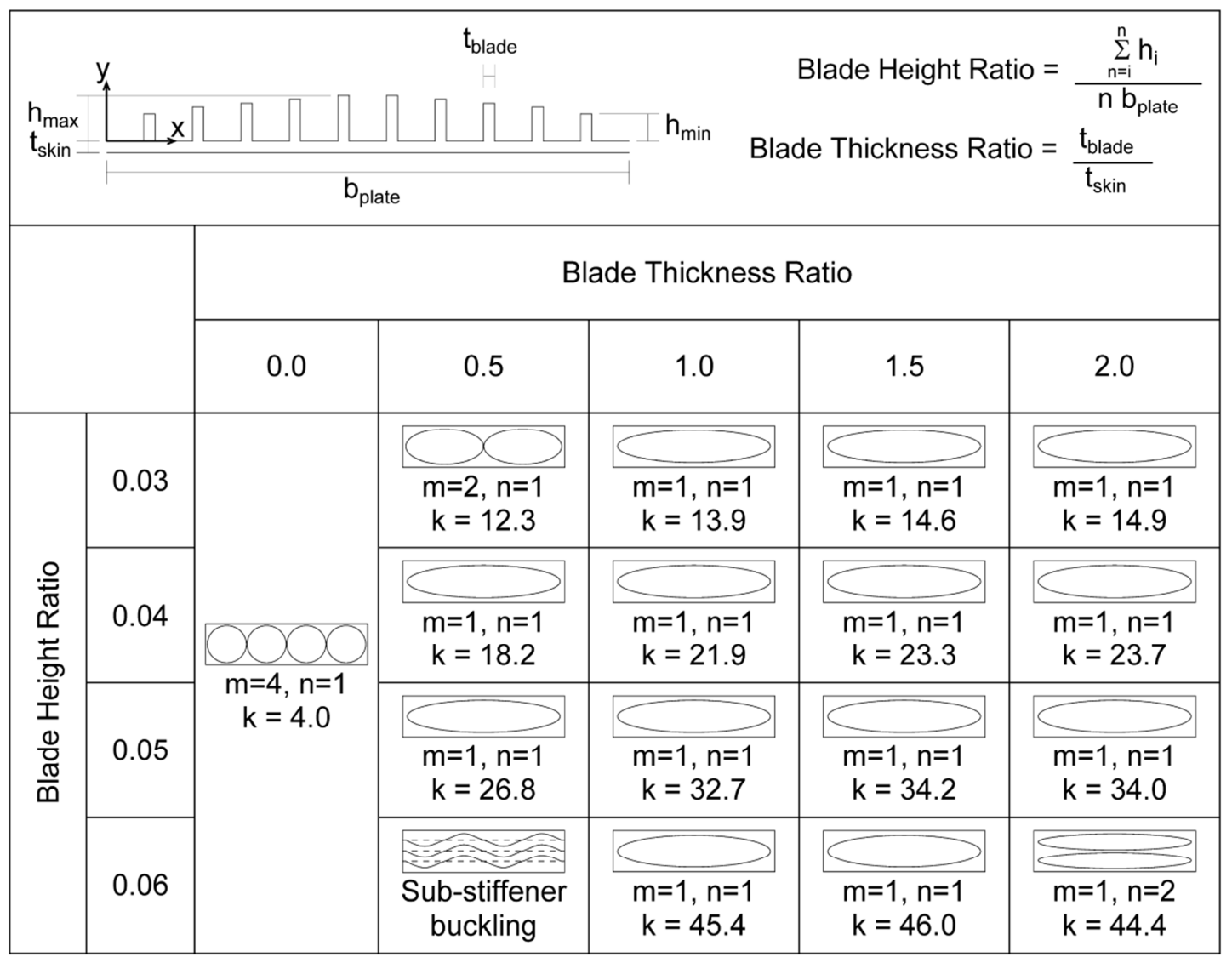

Figure 3 Sample buckling coefficient data for CASE PB2 (ten sub-stiffening blades, uniform blade thickness, aspect ratio 3.5, simply supported skin edges, and material constrained sub-stiffener edges). 


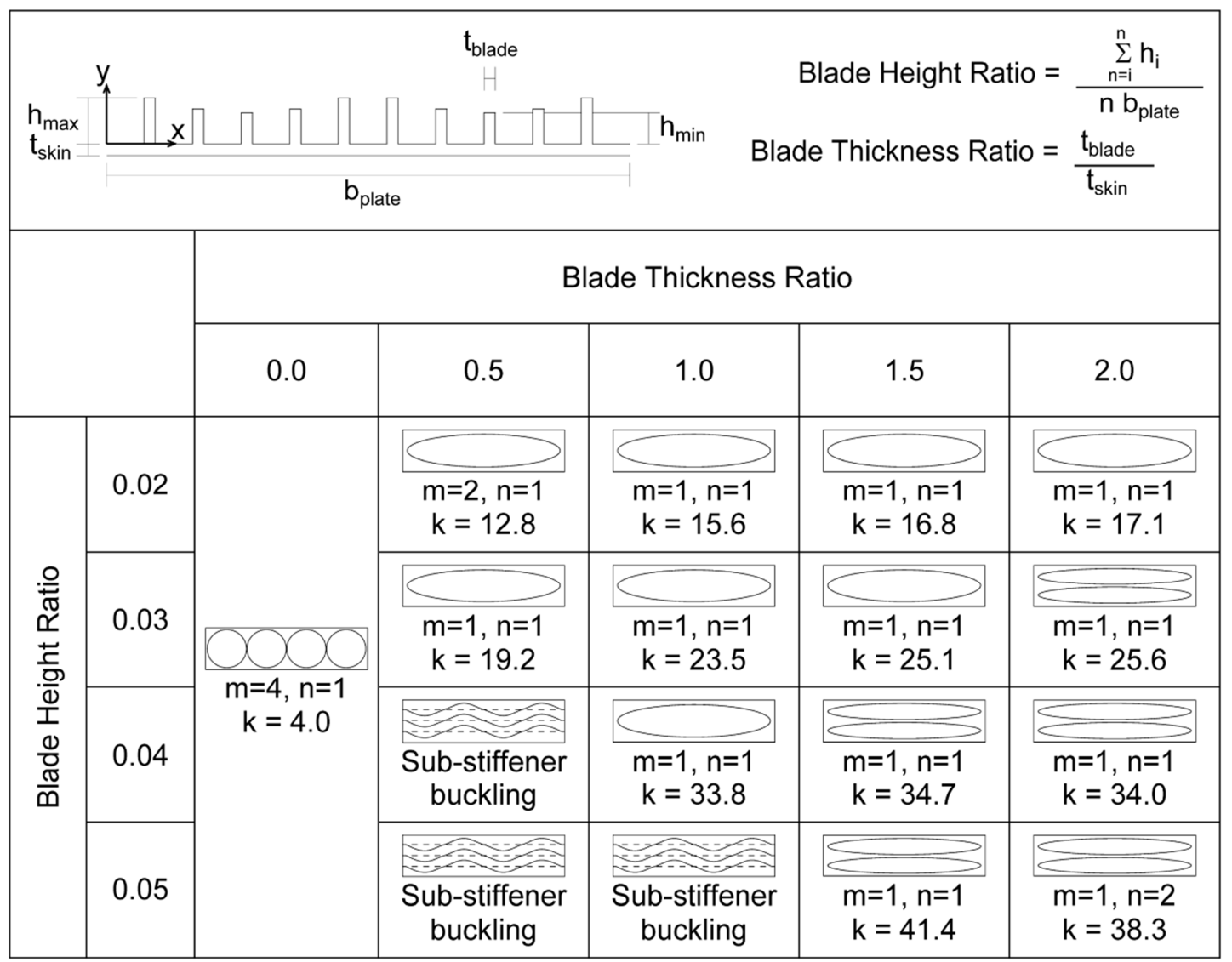

Figure 4 Sample buckling coefficient data for CASE PB3 (ten sub-stiffening blades, uniform blade thickness, aspect ratio 3.5, simply supported skin edges, and material constrained sub-stiffener edges). 

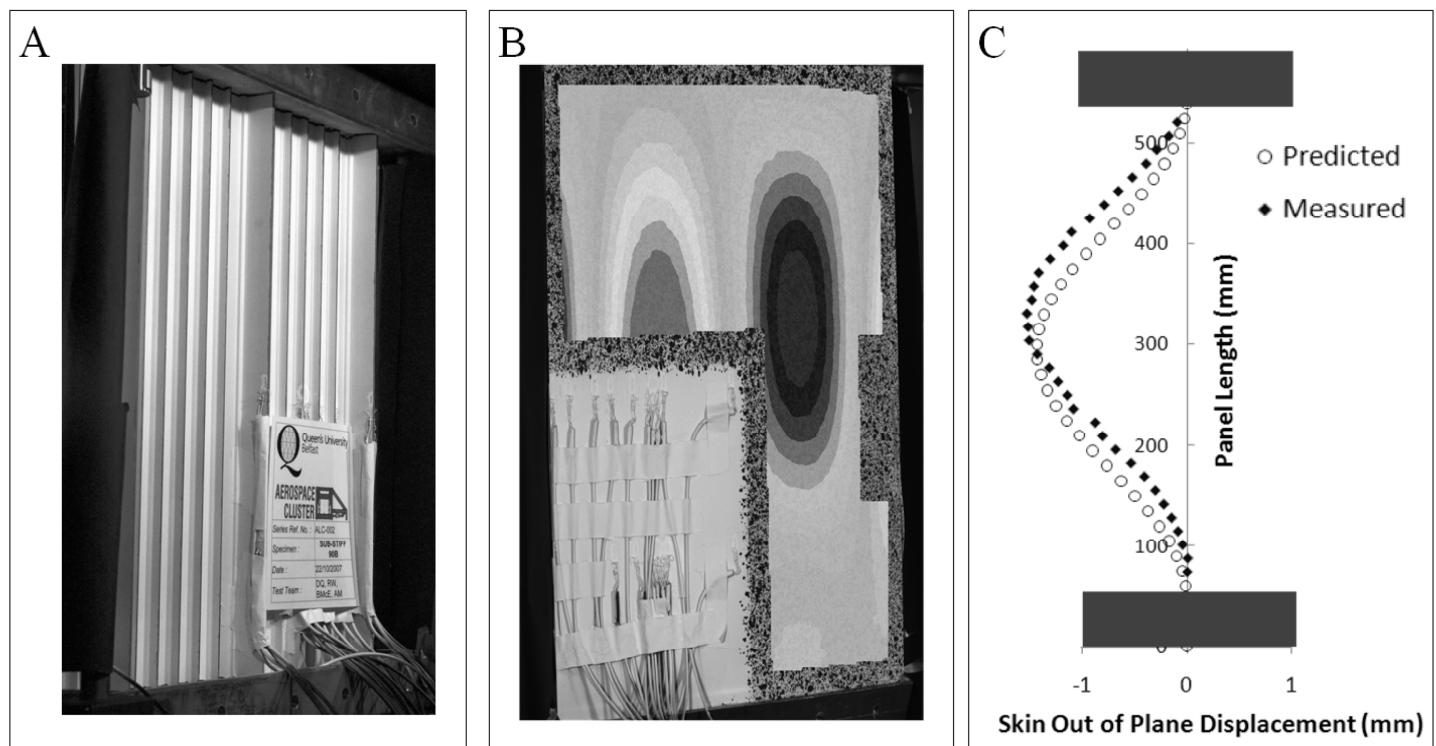

Figure 5 (A) the test specimen, (B) full field view of specimen initial skin buckling behaviour (3D DIC data), and (C) experimental and predicted mode shapes along the specimen skin-bay centre line. 

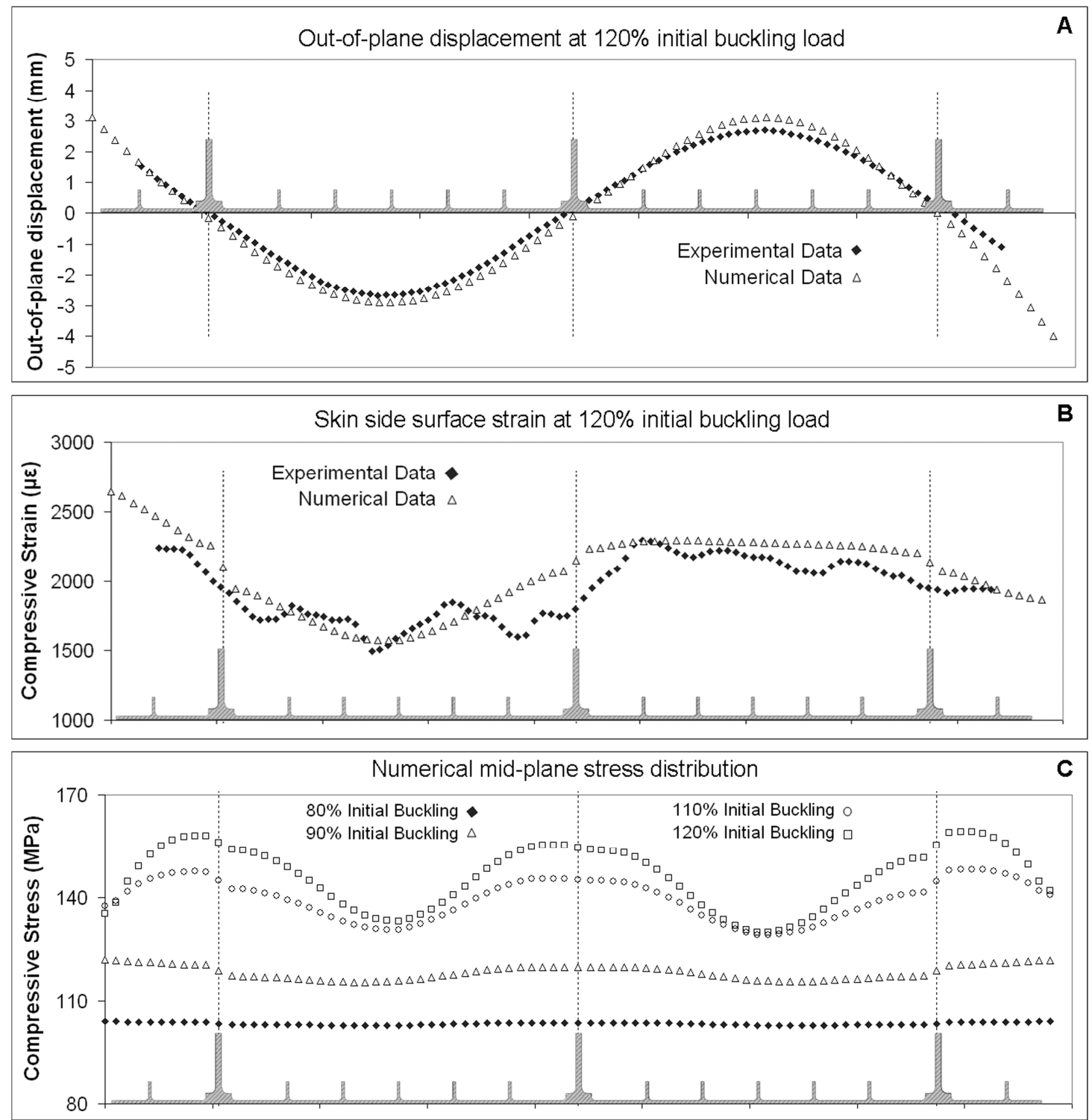

Figure 6 Measured and Finite Element predicted pre and post buckled (A) out-

of-plane displacement, (B) surface strains and (C) mid-plane stresses

data at the longitudinal centre line of the validation specimen ${ }^{14}$.

(Experimental surface strains measured using a 3D DIC system). 


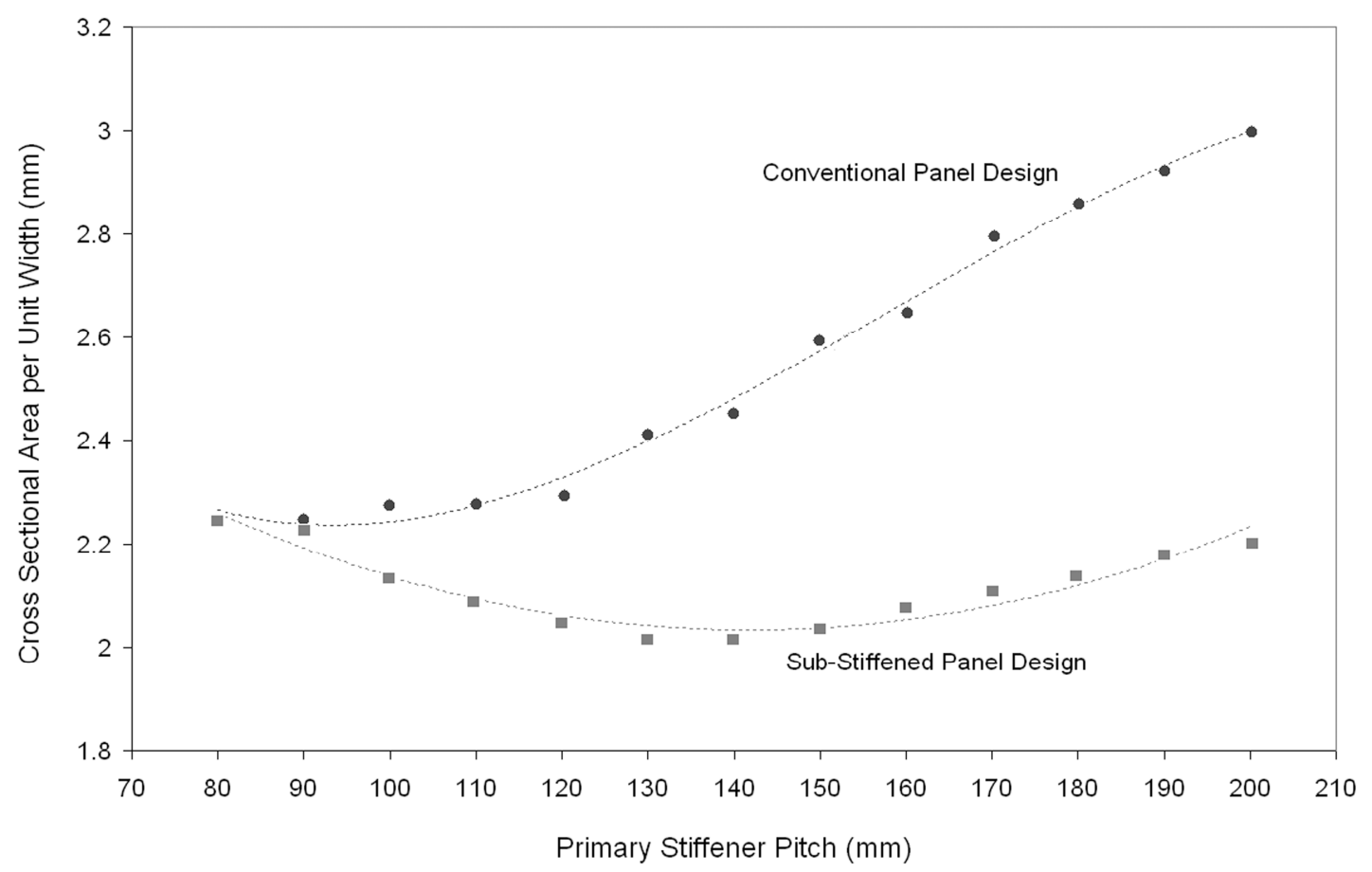

Figure 7 The relationship between primary stiffener pitch and minimum mass designs for conventional and sub-stiffened fuselage panels. 


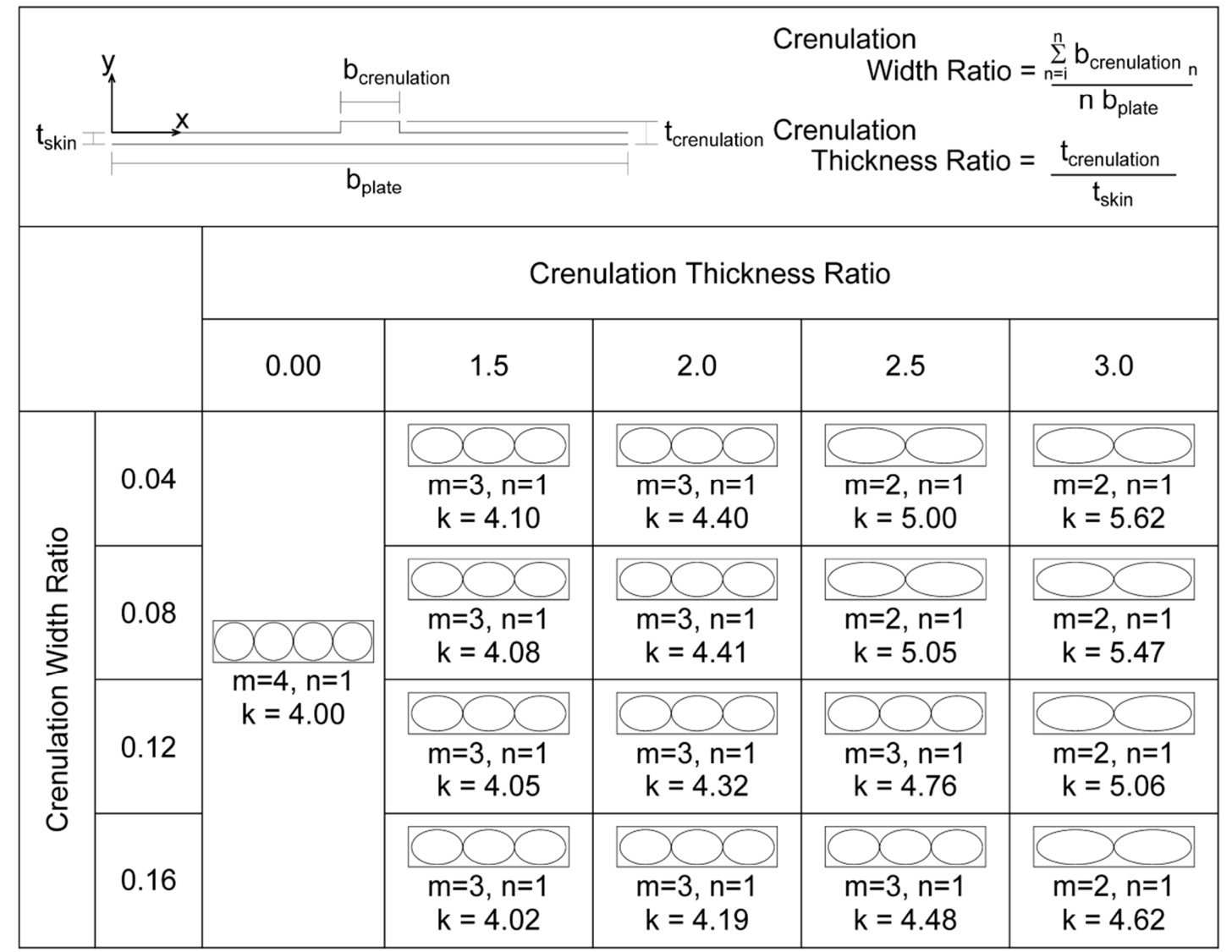

Figure 8 Sample buckling coefficient data for CASE PC1 (a single centrally located crenulation, uniform crenulation thickness, aspect ratio 3.5, simply supported skin edges, and material constrained crenulation edges). 


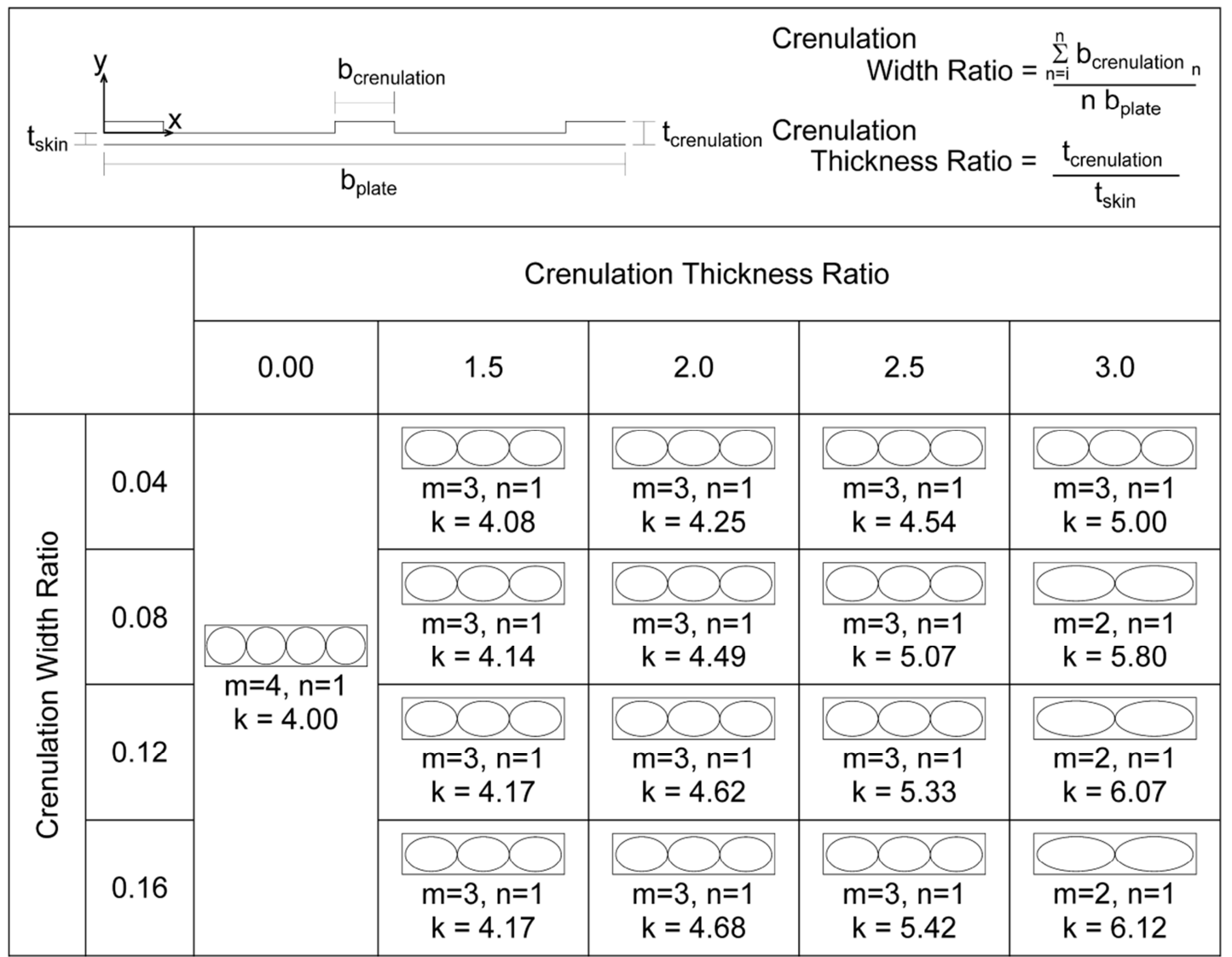

Figure 9 Sample buckling coefficient data for CASE PC2 (one central and two edge crenulations, uniform crenulation thickness, aspect ratio 3.5, simply supported skin edges, and material constrained crenulation edges). 


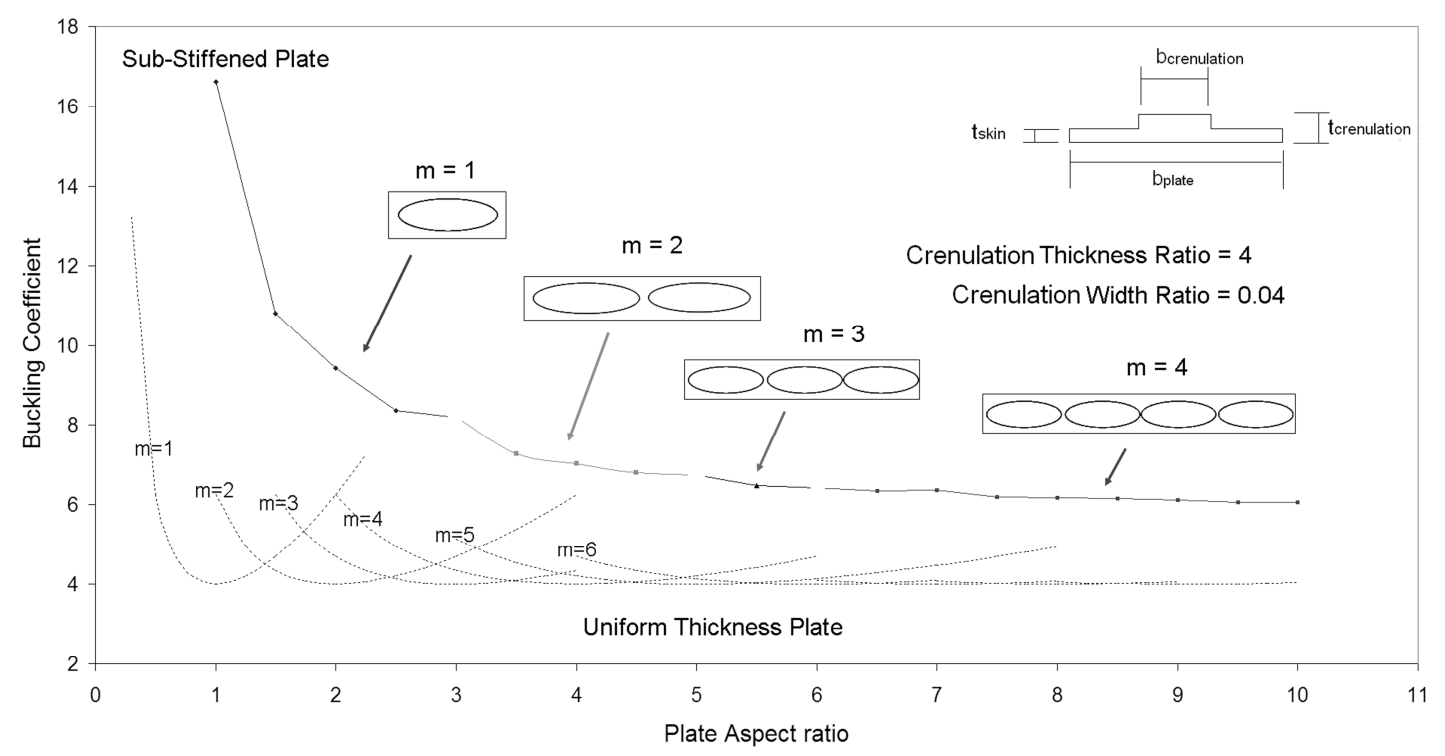

Figure 10 Relationship between stability performance and plate aspect ratio for a sample sub-stiffening configuration, crenulation thickness and width ratio. 
Table 1 Influence of design variables on mass and stability performance for case study one - Prismatic blades

\begin{tabular}{lcccc}
\hline \multirow{2}{*}{$\begin{array}{l}\text { A) Analysis of Means } \\
\text { Factors }\end{array}$} & \multicolumn{2}{c}{ Factor levels } & \multicolumn{2}{c}{ \% influence on response } \\
\hline Blade height $\left(\mathrm{h}_{\text {blade }}\right)$ & $5.0 \mathrm{~mm}$ & $10.0 \mathrm{~mm}$ & 51.0 & Plate mass \\
Number of blades & 3 & 6 & 15.8 & 21.0 \\
Skin thickness $\left(\mathrm{t}_{\text {skin }}\right)$ & $1.0 \mathrm{~mm}$ & $2.5 \mathrm{~mm}$ & 17.0 & 14.6 \\
Blade thickness $\left(\mathrm{t}_{\text {blades }}\right)$ & $1.0 \mathrm{~mm}$ & $3.0 \mathrm{~mm}$ & 10.5 & 47.2 \\
Spatial distribution & equal & clustered & 2.0 & 1.6 \\
& & & & \\
Interactions between: & & & 3.4 & 5.2 \\
Number of blades and blade thickness & & 0.2 & 1.0 \\
Blade height and number of blades & & & \\
\hline
\end{tabular}

\begin{tabular}{lcccc}
\hline B) Analysis of Variance & \multicolumn{2}{c}{ Factor levels } & \multicolumn{2}{c}{$\begin{array}{c}\text { \% deviation from mean } \\
\text { response }\end{array}$} \\
Factors & Lower & Upper & Plate stability & Plate mass \\
\hline Blade height $\left(\mathrm{h}_{\text {blade }}\right)$ & $5.0 \mathrm{~mm}$ & $10.0 \mathrm{~mm}$ & \pm 25.0 & \pm 4.9 \\
Number of blades & 3 & 6 & \pm 13.9 & \pm 7.3 \\
Skin thickness $\left(\mathrm{t}_{\text {skin }}\right)$ & $1.0 \mathrm{~mm}$ & $2.5 \mathrm{~mm}$ & \pm 14.5 & \pm 6.1 \\
Blade thickness $\left(\mathrm{t}_{\text {blades }}\right)$ & $1.0 \mathrm{~mm}$ & $3.0 \mathrm{~mm}$ & \pm 11.3 & \pm 11.0 \\
Spatial distribution & equal & clustered & \pm 5.0 & \pm 2.0 \\
\hline
\end{tabular}

${ }^{1}$ The blades are either equally spaced across the plate or clustered to the plate centre with a 2 to 1 ratio between the edge pitch and the central plate pitch. 
Table 2

Validation panel initial buckling and collapse loads

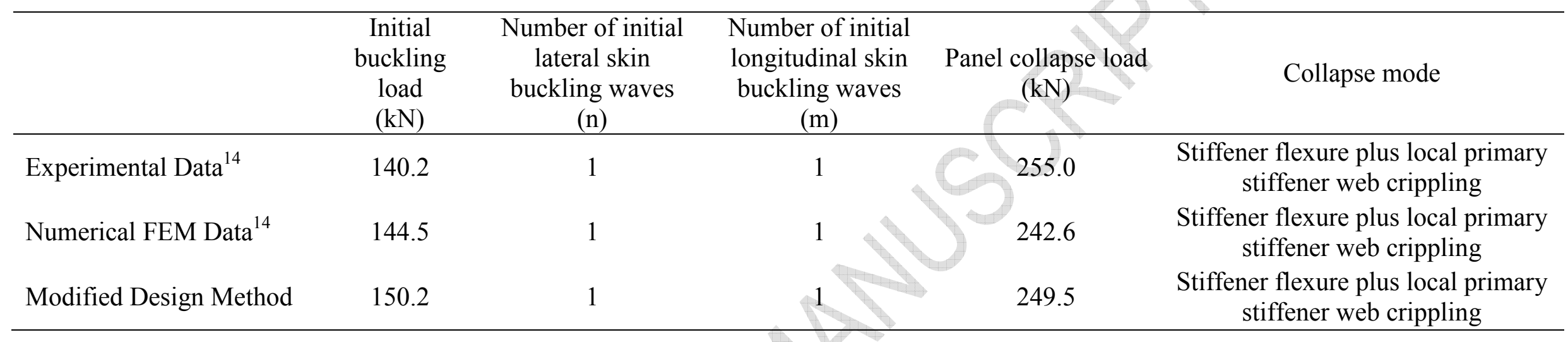


Table 3 Influence of design variables on mass and stability performance for case study two - Prismatic crenulations

\begin{tabular}{|c|c|c|c|c|}
\hline \multirow{2}{*}{$\begin{array}{l}\text { A) Analysis of Means } \\
\text { Factors }\end{array}$} & \multicolumn{2}{|c|}{ Factor levels } & \multicolumn{2}{|c|}{$\%$ influence on response } \\
\hline & Lower & Upper & Plate stability & Plate mass \\
\hline Skin thickness $\left(t_{\text {skin }}\right)$ & $1.0 \mathrm{~mm}$ & $2.5 \mathrm{~mm}$ & 21.0 & 45.4 \\
\hline $\begin{array}{l}\text { Total crenulation } \\
\text { thickness }\left(\mathrm{t}_{\text {crenulation }}\right)\end{array}$ & $3.0 \mathrm{~mm}$ & $6.0 \mathrm{~mm}$ & 5.6 & 19.9 \\
\hline $\begin{array}{l}\text { Crenulation width } \\
\left(\mathrm{b}_{\text {crenulation }}\right)\end{array}$ & $16 \mathrm{~mm}$ & $64 \mathrm{~mm}$ & 22.1 & 24.2 \\
\hline Crenulation location $^{1}$ & Centre & Edge & 7.1 & \\
\hline Crenulation orientation $^{2}$ & $0^{\circ}$ & $90^{\circ}$ & 32.2 & \\
\hline \multicolumn{5}{|l|}{ Interactions between: } \\
\hline \multicolumn{3}{|c|}{ Skin thickness and total crenulation thickness } & & 0 \\
\hline \multicolumn{3}{|c|}{ Crenulation width and total crenulation thickness } & & 0 \\
\hline
\end{tabular}

\begin{tabular}{|c|c|c|c|c|}
\hline \multirow{2}{*}{$\begin{array}{l}\text { B) Analysis of Variance } \\
\text { Factors }\end{array}$} & \multicolumn{2}{|c|}{ Factor levels } & \multicolumn{2}{|c|}{$\begin{array}{c}\text { \% deviation from mean } \\
\text { response }\end{array}$} \\
\hline & Lower & Upper & Plate stability & Plate mass \\
\hline Skin thickness $\left(t_{\text {skin }}\right)$ & $1.0 \mathrm{~mm}$ & $2.5 \mathrm{~mm}$ & \pm 68.5 & \pm 23.1 \\
\hline $\begin{array}{l}\text { Total crenulation } \\
\text { thickness }\left(t_{\text {crenulation }}\right)\end{array}$ & & $6.0 \mathrm{~mm}$ & \pm 35.5 & \pm 15.4 \\
\hline $\begin{array}{l}\text { Crenulation width } \\
\left(\mathrm{b}_{\text {crenulation }}\right)\end{array}$ & & $64 \mathrm{~mm}$ & \pm 70.2 & \pm 16.9 \\
\hline Crenulation location $^{1}$ & Centre & Edge & \pm 39.8 & \pm 0 \\
\hline Crenulation orientation $^{2}$ & $0^{\circ}$ & $90^{\circ}$ & \pm 84.8 & \pm 0 \\
\hline
\end{tabular}

${ }^{1}$ The single crenulation is located at the plate centre or two crenulations are located at the plate edge.

${ }^{2}$ The crenulated cross section is either parallel $\left(0^{\circ}\right)$ or perpendicular $\left(90^{\circ}\right)$ to the loading axis. 